\title{
CONVICÇÕES DE SAÚdE DE PAIS DE CRIANÇAS PORTADORAS DE DIABETES MELLITUS TIPO $\mathbf{1}^{\star}$
}

\author{
Sue Ellen Ferreira Modesto $\star$ \\ Maria Geralda Viana Heleno $\star \star \star$
HeAlth Beliefs of PARENTS OF CARRYING CHILDREN WITH DIABETES MELLITUS TYPE 1

\begin{abstract}
Resumo
O Diabetes Mellitus tipo 1 geralmente ocorre na infância ou adolescência e repercute de forma dramática na vida dos pais. A família é fundamental no tratamento do paciente: representa o alicerce que influenciará na aceitação ou não da enfermidade por parte do portador. Por isso, os objetivos deste estudo foram descrever as conviç̧ões de saúde de pais de crianças portadoras de diabetes mellitus tipo 1 e compreender mudanças comportamentais e psíquicas que possam influenciar na conduta em relação ao tratamento. Investigou-se 13 pessoas, pais de crianças de 11 meses a 10 anos portadoras de Diabetes Mellitus Tipo 1, por intermédio de uma entrevista para levantamento e descrição de fatores de convicção de saúde. Os dados foram avaliados com base em um modelo de "convicção de saúde". Esse modelo avaliou: impacto do diagnóstico, suscetibilidade, severidade, beneficios, barreiras, eficácia própria e expectativa de futuro de cada um dos pais. Os resultados mostraram que os pais experimentam dificuldades, medos e inseguranças, pela doença do filho. Ao relatarem as situações vividas desde o diagnóstico até o momento atual, em todas as etapas, os pais revelam intenso sofrimento. Eles são constantemente invadidos por medo de perda tanto no presente como no futuro em função das complicações da doença. A partir desses resultados recomenda-se que os pais recebam atendimento de uma equipe multidisciplinar com conhecimento especifico e com a finalidade de informar sobre a doença e aplacar os medos e inseguranças que criam obstáculos para a adesão ao tratamento. Espera-se com este tipo de atendimento melhorar a qualidade de vida do paciente e de sua família.
\end{abstract}

Palavras Chaves: Diabetes Mellitus Tipo 1. Cuidadores. Aspectos Emocionais.

\footnotetext{
* Dissertação apresentada ao Programa de Pós-Graduação em Psicologia da Saúde, da Universidade Metodista de São Paulo (UMESP), como requisito parcial para obtenção do título de Mestre em Psicologia da Saúde.

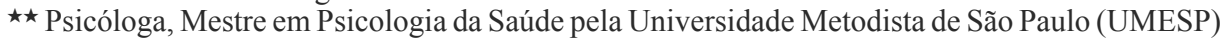
e Especialista em Psico-Oncologia pelo Hospital A.C. Camargo. Correspondência: Rua Rússia, no 410, Bairro: Santa Rosa. Cep: 78040-320. Cuiabá-MT.

E-mail: suemodesto@hotmail.com

$\star \star \star$ Doutora em Psicologia Clínica pela Universidade de São Paulo (USP) e Professora do curso de Mestrado em Psicologia da Saúde da Universidade Metodista de São Paulo (UMESP).
} 